\title{
Digitalisation Practices in South-African State-Owned Enterprises: A Framework for Rapid Adoption of Digital Solutions
}

\author{
Ephraim Thapedi Malope \\ Graduate School of Business \\ Leadership (SBL) \\ University of South Africa \\ Midrand, South Africa \\ thapedimalope@yahoo.com
}

\author{
John Andrew van der Poll \\ Graduate School of Business \\ Leadership (SBL) \\ University of South Africa \\ Midrand, South Africa \\ vdpolja@unisa.ac.za
}

\author{
Ozias Ncube \\ Graduate School of Business \\ Leadership (SBL) \\ University of South Africa \\ Midrand, South Africa \\ ncubeo@unisa.ac.za
}

\begin{abstract}
The dawn of the 4IR ( $4^{\text {th }}$ Industrial Revolution) brought about numerous opportunities for digitisation of South African State-Owned Enterprises (SOEs). Yet, it is uncertain to what extent these SOEs are positioned to embrace 4IR opportunities and address the challenges. In this paper we investigate the value of SOEs in South Africa (SA) as a developing economy as well as important components of the 4IR and SA government initiatives to embrace the 4IR. Amongst others, Blockchain, Advanced Analytics, AI, and the IoT have been identified as important 4IR components. On the strength of a literature review, a number of propositions is defined and these together with existing technology adoption frameworks, notably the TechnologyOrganisation-Environment (TOE) framework are used to define a digitalisation framework for 4IR adoption by SA SOEs. Key to the framework is collaboration among individuals in the 4IR. The framework is subsequently validated conceptually by linking it to the stated propositions.
\end{abstract}

\section{Introduction}

The Fourth Industrial Revolution (4IR) is making inroads into world economies, featuring as a key agenda item at the World economic forum (WEF) held in Davos, in January 2016 and continues to feature on its agenda annually. The WEF defines the 4IR as a technological revolution that connects digital technology with bio-technology and physics on the strength of the 3rd Industrial Revolution [1]. There is already evidence of the quality of service (QoS) offering and product production brought about by the 4IR into the world.

South African SOEs (State-Owned Enterprises) have a major role to play in advancing the economy of South Africa (SA) through the adoption of the 4IR and mass skills development. The digital economy that can be unlocked through the SOEs in South Africa are vast and ought to be pursued purposefully.

South Africa as a developing country has lucrative potential and influence in Southern Africa and Africa at large. It is labelled as the fastest growing economy and second largest economy in Africa after Nigeria and $32^{\text {nd }}$ in the world with a gross domestic product (GDP) of US\$349.4 billion [2] and also recognised as the African leader in terms of the Network Readiness Index and ranked 65 in the world [3].The inclusion of SA in the BRICS (Brazil, Russia, India, China, and South Africa) group, is further recognition of its significance in Africa.

The dawn of the 4IR likewise holds promise for developing economies. To this end 4IR opportunities are frequently discussed at economic gatherings of governments and businesses, and, therefore, ought not to be ignored by SA, its SOEs and all other businesses if they are committed to growth and participation in the advancing new economy. Consequently, in this paper the researchers investigate the 4IR digitalisation opportunities for SOEs in South Africa as a developing economy. In doing so we formulate a number of qualitative propositions used primarily to develop a digitalisation framework for SA SOEs in the 4IR.

The layout of the paper is: Following the introduction, our research questions (RQs) and the objective pursued in addressing the RQs are presented next. Cognizance of the RQs are given at various points in the paper. Our research methodology is briefly espoused in Section 2, while Section 3 which embodies the literature review addresses numerous aspects that underlie the 4IR. Throughout the paper we formulate a number of qualitative propositions to assist in developing a conceptual framework for South-African SOEs (State-Owned Enterprises) to venture into the 4IR in Section 4. A theoretical validation of the framework is presented in Section 5, followed by a conclusion and directions for further work in this area in Section 6. 
Our research aims to answer the following research questions (RQs):

1. What is the relevance of SOEs in South Africa as a developing economy? (RQ1)

2. What are the major components of the 4IR applicable to SA SOEs? (RQ2)

Our objective is to:

- Develop a framework for SA State-Owned Enterprises (SOEs) as a developing economy to venture into the 4IR.

\section{Research Methodology}

The research methodology in this paper follows the processes in Saunders et al.'s Research Onion [4], as illustrated in Figure 1.

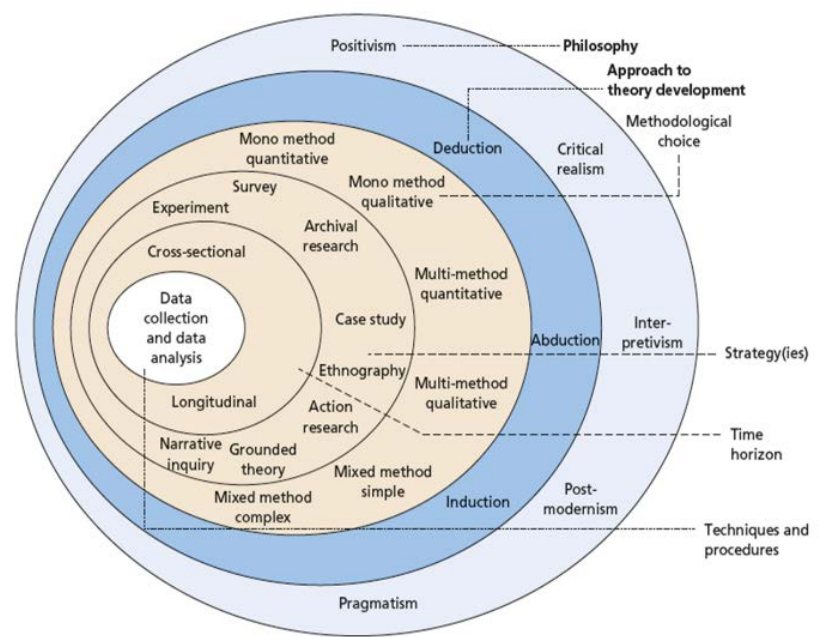

Figure 1: Research trends and adoption categories [4]

As per Figure 1, the research philosophy in layer 1 is interpretivist, since the researchers interpreted the literature in terms of qualitative texts and diagrams. As per the $2^{\text {nd }}$ layer, our approach followed is abductive inductive framework construction, followed by a deductive phase, namely, the validation of the framework. The methodological choice is mono qualitative, owing to the fact that we interpreted qualitative texts. Our strategy involved literature- and case study surveys. The time horizon is cross-sectional since the work was done over a relatively short period of time, namely, 18 months. Our data collection and analyses were conceptual in terms of the literature review.
An extensive literature review around digitalisation of SOEs with specific reference to the 4IR was undertaken. Aspects that emerged are presented below.

\section{Literature Review}

\subsection{What is the Fourth Industrial Revolution (4IR)?}

Generally the 4IR is defined as technological developments that blur the lines between the physical, digital and biological spheres and integrates cyberphysical systems and the Internet of Things (IoTs); Big data; Cloud computing (CC); Robotics; Artificial intelligence-based (AI-based) systems; Advanced Analytics; and Additive manufacturing. Compared to previous industrial revolutions, the 4IR is evolving at an exponential rather than a linear pace, with potentially significant impacts on work, services, education and leisure [5] [6].

\subsection{IR in SA and SA SOEs}

South Africa like many other countries have several SOEs, wholly or partially owned - there are currently in the order of 715 SOEs, inclusive of municipalities, trusts and section 21 companies. As with the developed economies, South African SOEs are considered important agents of change to contribute to the economy, social transformation, creation of decent jobs, growth, and development of the society. SA is ranked 49th out of 63 top countries in the world on digital competitiveness [7]. Imperative in the drive towards the 4IR is adherence to aspects of service quality for SA SOEs [8].

According to Gumede [9] the SA National Development Plan (NDP) 2030 is being purported as the new blueprint to effect economic growth and opportunities in SA, largely through the use of SA SOEs, and a mixture of state ownership and privatisation. Technology advancement, global and social economics are also the driving forces that require the SA SOEs to restructure in order to achieve rapid growth and contribute to the socio-economic development of SA or become extinct. Like its global counterparts, and as indicated SA have a variety of SOEs and large to small multinationals and can benefit from digitalisation adoption to further growth, especially through advancing digital competitiveness in the world, through digital infrastructure, a strong regulatory environment, government recognition of the 4IR, and world-recognised institutes of learning and R\&D (Research and Development). 


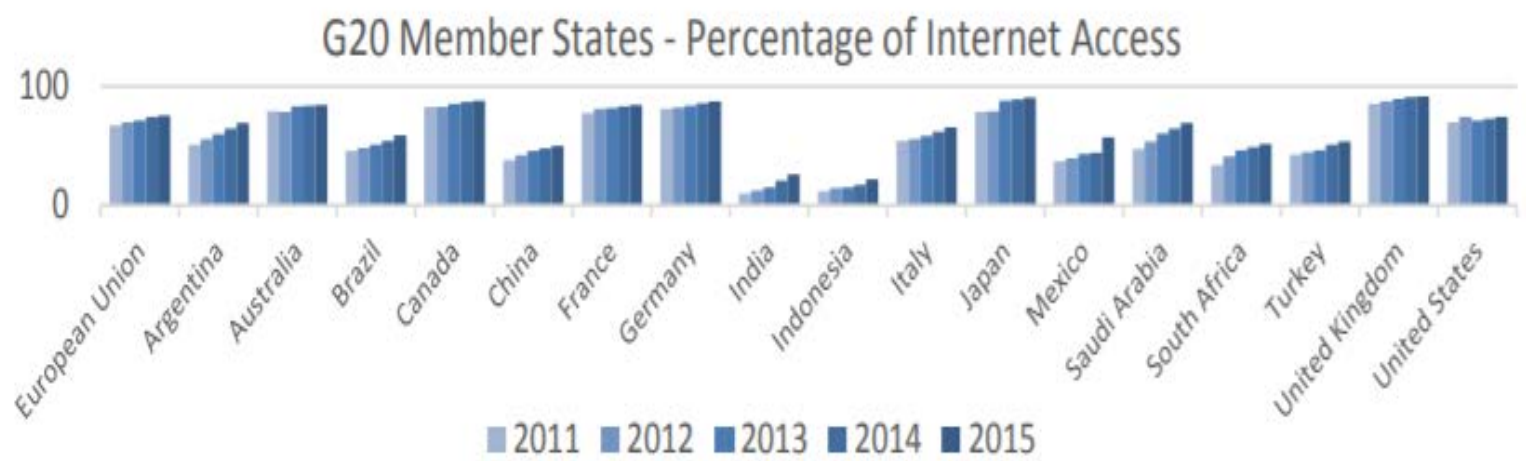

Figure 2: Percentages of individual using the internet on the G20 member state [11]

As reported by Kumar [10] the current President of SA, Mr. Cyril Ramaphosa, in his first State of the Nations Address (SONA) 2018 speech, confirmed government commitment to the 4th Industrial Revolution (4IR). The President further committed to establishing a 4IR Committee to be comprised of all relevant stakeholders, the private sector, civil society, etc., to ensure the country is positioned to embark on opportunities of Digitalisation.

As indicated SA is ranked 49th out of 63 top countries in the world on digital competitiveness with the following further classification: Digital Knowledge and Technology measured at 52nd, and Future readiness at 43rd in the world [7]. The Weforum [3] also measured the digital transformation of SA as 32nd in the world for business, 77th by individuals and 105th by government usage, and SA is also among the top 20 countries globally with internet infrastructure and bandwidth. However, SA business executives perceive the country to be performing well on regulatory and political arenas but challenged on innovation and the business environment.

Figure 2 illustrates the ranking of percentages of individuals using the Internet on the G20 member states The observation by Chetty et al [11], in Figure 2, on the Group of 20 (G20) countries (an international forum with 19 countries and the 20th being the European Union), as in WikiG20 [12], elicited that SA is ranked low on internet access by its population, with about 35\% of the South African population seeing no relevance in accessing the internet. Yet, it's still considerably better than India, China, and Indonesia who are also members of the G20.

The preceding discussions, especially the above presidential announcement, digital competitiveness and internet penetration lead to a preliminary version of the $1^{\text {st }}$ proposition in the construction of our framework:
- Prop 1.1: Digitalisation practices of SA SOEs ought to embed principles of the 4IR.

The above proposition will be refined following more detailed discussions regarding the 4IR later in this paper.

The foregoing discussion also answers our RQ1, namely, the relevance of SA SOEs in a developing economy.

\subsection{SOEs Global perspective}

Like other states Vietnam SOEs have a share of national investment in land, property and other physical assets which are relatively efficient and productive. It's also noted that the SOEs are expected to be rather inefficient compared to other companies, even though they are not necessarily subject to hard budget constraints, are entitled to state guarantees on their credits, which are privileges that are not readily available to private enterprises [13].

Studies on Chinese SOEs, emphasise that the SOEs are fundamental to socio-political and economic stability and that most of their SOEs have issues of inertia, huge headcount, debts, and waste, challenges common in other states SOEs. As much as affected by local regulation, the globalisation strategy has put pressure on the SOEs to be more transparent and responsible in their operations, as demanded by international trading regulations [14].

Clegg et al [15] reported that $19 \%$ of Forbes Global 500 companies in 2011 were state-owned and that the number would have been in excess of $22 \%$ by 2018. The SOEs in high-technology industries e.g. nuclear power generation, telecoms, banking, constructions etc., are reported to be expanding globally, therefore, they are now State-Owned Multinational Companies (SOMNCs). However, many face multiple challenges, e.g. shortage of skilled resource, social policies, politics, regulations, etc. of the 
hosting country, therefore, the strategy to internationalise the SOEs ought to be designed and executed carefully to avoid substantial failure and losses [15]. Note how this discussion supports Prop 1.1 above. The above observations lead to our $2^{\text {nd }}$ (in essence an overarching) proposition:

- $\quad$ Prop 2: Digitalisation ought to play a major role in multinational (and in essence SA) SOEs to rollout their strategies and compete globally.

\subsection{Technology Mega-trends and Adoption Categories}

Woodside et al. [16] identified five (5) technology mega-trend for 2017 as being: Analytics (machine learning and $\mathrm{AI}$ ), Cloud Computing (CC), Internet of Things (IoT), Virtual and augmented reality (V\&AR), and Block-chain. Later work by Bayode et al. [5] in 2019 confirmed these technology megatrends.

Figure 3 synthesised from the work by Clegg et al. [15] in 2018 indicates the five top trends and adoption categories in which innovators and early adopters come in well below $10 \%$, early and late majority at an average of $34 \%$ and the laggards at $16 \%$.

\section{Top Tech Trends and Adoption Categories} 1 Analytics (Machine learning and Al), 2 Cloud computing, 3 Internet of Things, 4 Virtual Augmented Reality, 5 Blockchain

Laggards(16\%) normally last to adopt new technology, and mostly by they adopt the innovators has already completely on the next sets of phases of innovation.

Late Majority (34\%) more skeptical and cautious of new tech and adopt after being convinced by others

Early Majority (34\%) get on board halfway point of adoption and might to decide

Early Adopters(13.5\%) acts as through leaders and change agents

Innovators(2.5\%) this is mostly technology service providers and partners and other top companies, which are adventurous, high risk tolerance, and mainly have strong financial backing

\section{Figure 3: Five Top Tech Trends and adoption categories (Synthesised from [15])}

The above discussions as well as the information in Figure 3 lead to two (2) propositions:

- Prop 3: For SOEs to derive meaningful benefits from digitalisation they should decisively move from being laggards to at-least early adopters.

- $\quad$ Prop 4.1: The top 4IR digitalisation categories that SOEs ought to embark on are Analytics, Cloud
Computing (CC), the IoT, and Block-chain technologies.

Prop 4.1 is preliminary since further discussion below will augment it.

The following section focuses on some of the aforementioned megatrends and their adoption analyses.

\section{Block-chain}

Woodside et al. [16] analysed the adoption of Blockchain and other Digital technologies and indicated the following in their research:

- Environment analyses: These involve analyses of Political, Economic, Social, Technical, and Legal (so-called PESTL analyses) aspects.

- Text Analyses: The text analytics done on major companies (Fortune 50) financials summaries and other public strategic documents found little or no evidence of the use or mention of block-chain as compared to other Digital concepts. Block-chain was mentioned only by IBM, virtual/augmented reality mentioned by only by Alphabe and Microsoft, IoTs by 10 companies, CC by 22 companies, and analytics/AI by 26 companies.

- Financial analysis: There was over $\$ 1.4$ billion worth in block-chain start-ups in 2016 alone and the big four accounting companies, have invested in research and some level of adoption of the blockchain technology. The tracked total of over 900 crypto-currencies have a market value of $\$ 91$ billion and as in 2017 these amounted to approximately $5.8 \%$ of the total currency in circulation in the US [16].

Note how the information on the financial analyses reinforce our proposition 4.1 above.

The above discussions lead to our $5^{\text {th }}$ proposition:

- $\quad$ Prop 5: Some of the major challenges of SOEs for digitalisation are lack of digital leadership, lack of skills, high cost of skills and/or adoption thereof, lack of awareness, security concerns, and lack of compliance.

\section{Advanced Analytics}

Despite benefits of digitalisation, Ravi et al. [17] report analytics in the cloud to face challenges such as, security, service levels, governance, privacy, etc. If the majority of solutions are already executed in the cloud, it would make sense to have analytics managed from the cloud. Google, Amazon, Microsoft and Cloudera already have applications available offered through CC to address big data analytics. 
Table 1 describes the various tools available.

Table 1: Big data analytics applications (Source: Ravi et al. [17])

\begin{tabular}{|c|c|c|c|c|}
\hline & $\begin{array}{l}\frac{0}{0} \\
\dot{8} \\
0\end{array}$ & 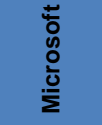 & 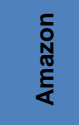 & $\begin{array}{l}\frac{\pi}{\frac{\pi}{0}} \\
\frac{0}{0} \\
\frac{0}{U}\end{array}$ \\
\hline 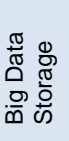 & 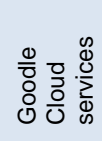 & 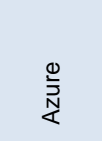 & $\tilde{\omega}$ & \\
\hline 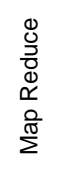 & 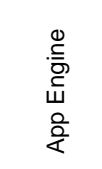 & 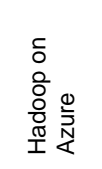 & 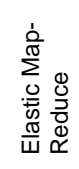 & 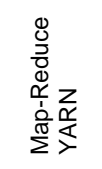 \\
\hline 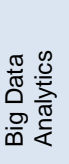 & 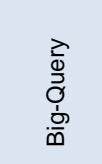 & 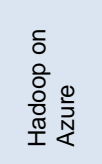 & 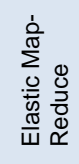 & 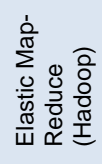 \\
\hline 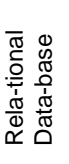 & $\begin{array}{l}\overrightarrow{0} \\
0 \\
\frac{0}{0} \\
\frac{0}{0}\end{array}$ & 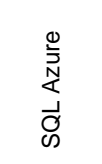 & 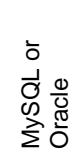 & 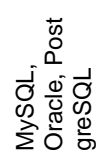 \\
\hline 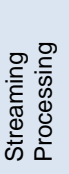 & $\begin{array}{l}\overline{\frac{1}{4}} \\
\frac{1}{0} \\
\overline{0} \\
\stackrel{0}{0} \\
\text { n }\end{array}$ & 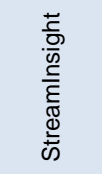 & 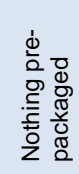 & $\begin{array}{l}\text { ․․ } \\
\frac{0}{0} \\
\text { की } \\
\frac{0}{0} \\
\frac{\pi}{\pi} \\
\frac{0}{<}\end{array}$ \\
\hline 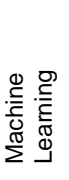 & $\begin{array}{l}\overline{0} \\
\bar{\alpha} \\
\overline{0} \\
\overline{0} \\
\overline{0} \\
\overline{0} \\
\overline{0}\end{array}$ & $\begin{array}{l}+\frac{0}{0} \\
\frac{0}{0} \\
\frac{0}{0} \\
\frac{0}{0} \\
\frac{\pi}{1} \\
\frac{\pi}{2}\end{array}$ & $\begin{array}{l}+ \\
\frac{0}{0} \\
\frac{0}{0} \\
\frac{0}{0} \\
\frac{\pi}{1} \\
\frac{\pi}{2}\end{array}$ & 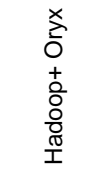 \\
\hline 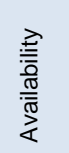 & 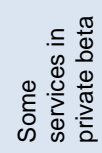 & 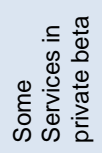 & 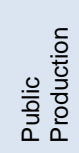 & 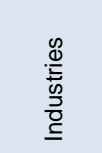 \\
\hline
\end{tabular}

\section{Artificial Intelligence (AI)}

Anselma et al [18] in their studies on AI, alluded to the use of intelligent wearables that can be used to monitor human behaviour and, therefore, improve our health and deal with transgressions. Data can be collected automatically or manually by the wearable or app devices on our exercise patterns, the intensity of the exercise, the diet we consume, and many other activities. Anselma et al. [18] suggest further improvement or changes for humans. AI, besides generating big data, play an important role in the analysis of big data that could be generated by other sources, e.g. machine learning or the operations of robots.

The above discussion augments our Proposition 4.1 to:

- $\quad$ Prop 4: The top 4IR digitalisation categories that SOEs ought to embark on are Analytics, Cloud Computing (CC), the IoT, and Block-chain technologies. Of particular importance is the use of intelligent computing wearables to protect and improve human health.

Davenport and Ronanki [19] note that businesses should consider AI in business capabilities instead of just technology ones. They also described three types of AIs, being process automation, which is about the automation of digital and physical tasks e.g. back-office work, robots, ATMs etc., secondly cognitive insight, which is about analyses of big data i.e. advanced analytics, and thirdly cognitive engagement which deals with engaging customers and employees using natural language processing chatbots, intelligent agents, and machine learning. Most organisations use cognitive engagement with their staff instead of customers [19].

SOEs in SA have different needs which require different business capabilities and therefore one size fits all may not be applicable to the adoption of AI solutions, yet there might be some common challenges that can be address by common solutions, e.g. supply chain and procurement challenges, leading to violation of some governance laws like the PFMA (Public Finance Management Act), corruption, fruitless expenditure, fraud and so forth. Common AI solutions can be adopted to assist in resolving some of these challenges, being through analytics, digital or some physical devices. SA SOEs can play a major role in advancing AI to their own advantage, the government and the public at large.

The above discussions on robotics and AI refine Prop 1.1 above:

- Prop 1: Digitalisation practices of SA SOEs ought to embed the principles of the 4IR. High tech SOEs ought to embed AI principles including robotics where appropriate.

\section{Internet of Things (IoTs)}

Gubbi et al. [20] indicated that the IoTs since stepped out of its infancy and is on the verge of transforming the current static Internet into a fully integrated Future Internet. With people already interconnected at an unprecedented scale and pace, the next revolution is about the interconnection of objects to create a fullfledge smart environment. Furthermore, they report that the number of interconnected objects on the planet 
overtook the actual number of people, with over nine billion interconnected objects in 2013 already, and that number is expected to reach about 24 billion by the end of 2020 [20]. As illustrated by the Horizon 2020 framework, which funds research and innovation in Europe, the numerous issues faced by the society can, to some extent be addressed by IoTs.

The challenges faced by society are classified as health; demographic change and wellbeing; food security and sustainable agriculture; secure, clean and efficient energy; smart-, green- and integrated transport; climate action, environmental aspects; resource efficiency and raw materials; inclusivity; and innovative, reflective and secure societies [21]. SA SOEs mostly participate and have some stake in all these areas, e.g. Eskom and PetroSA, in the energy sector; and Prasa and SAA in the transport sector. Naturally these organisations can reap substantial benefits towards the use of IoTs to bring efficiency into their organisations and in the process address some of these societal challenges. Table 2 illustrates the expected major contributions of IoTs systems in addressing the societal challenges [21].

Table 2: Contributions of loTs (Source: [21])

\begin{tabular}{|c|c|c|}
\hline $\begin{array}{l}\text { Societal } \\
\text { challenges }\end{array}$ & $\begin{array}{l}\text { IoT major } \\
\text { contribution }\end{array}$ & $\begin{array}{l}\text { IoT systems } \\
\text { desired features }\end{array}$ \\
\hline $\begin{array}{l}\text { Health and } \\
\text { wellbeing }\end{array}$ & $\begin{array}{l}\text { Monitoring } \\
\text { health }\end{array}$ & $\begin{array}{l}\text { Pervasivity, } \\
\text { Transperency, } \\
\text { wear-ability, } \\
\text { security }\end{array}$ \\
\hline Food security & Smart farms & $\begin{array}{l}\text { Usability, } \\
\text { Sustainability }\end{array}$ \\
\hline Clean energy & Smart grids & $\begin{array}{l}\text { Stringent QoS, } \\
\text { adaptivity }\end{array}$ \\
\hline $\begin{array}{l}\text { Green } \\
\text { transport }\end{array}$ & $\begin{array}{l}\text { Logistics } \\
\text { management }\end{array}$ & Interoperability \\
\hline Enviroment & Smart cities & $\begin{array}{l}\text { Distributed local } \\
\text { awareness }\end{array}$ \\
\hline $\begin{array}{l}\text { Innovative } \\
\text { societies }\end{array}$ & $\begin{array}{l}\text { New } \\
\text { opportinities }\end{array}$ & Collaboration \\
\hline $\begin{array}{l}\text { Secure } \\
\text { societies }\end{array}$ & $\begin{array}{l}\text { Automatic } \\
\text { detections }\end{array}$ & Security \\
\hline
\end{tabular}

The role of government in removing the challenges and creating an environment that encourages innovation is significant for the success and adoption of IoTs. The South African commitment of Digitalisation at the government level, as even reflected in the NDP is therefore a step in the right direction. SOEs being state controlled are also highly dependent on government commitment to create a conducive environment for digitalisation to thrive. Atzori et al. [21] alluded that the public authorities can play a role to foster IoTs by promoting the diffusion of open IoTs' data and processes, fostering the utilisation of the IoTs' infrastructure in a city's management, and by introducing regulatory changes to facilitate smooth adoption.

Note how the discussions on the IoT in the preceding paragraphs support Prop 4 above.

\section{SA Digitalisation Highlights}

As alluded to before, SA is ranked 49th out of 63 top countries in the world on digital competitiveness with the following further classification, Digital Knowledge and Technology measured at 52nd, Future readiness at 43rd in the world [7]. The WEF [3] also measured the digital transformation of SA as 32nd in the world for business, 77th by individuals and 105th by government usage, and placed SA also among the top 20 globally with internet infrastructure and bandwidth.

SA business executives, however, perceive the country to be performing well on regulatory and in the political arena but challenged on innovation and business environments. There are indications of deterioration in technology and venture capital availability that persists despite the investment in infrastructure, increase in the internet bandwidth, and reductions in mobile and broadband tariffs [3] .

Some of the highlights of SA participation in digitalisation are:

- $\quad$ The Teacher Laptop Initiative (TLI) [22]

- $\quad$ SA participation in the SKA (Square Kilometre Array) project [23]

The discussions in this section place emphases on individuals, hence our last proposition with two subcomponents:

- $\quad$ Prop 6: Business executives have a major role to play in the digitalisation of SOEs. In particular:

- Prop 6.1: Innovation initiatives and Knowledgemanagement collaboration among individuals ought to be promoted.

- $\quad$ Prop 6.2: Executives are to facilitate training of employees and funding in the SOE.

The discussion in this Section 3 provides an answer to our research question RQ2, namely which 4IR components are applicable to SA SOEs.

Next, we develop our digitalisation framework synthesised from the literature and propositions defined above. 


\section{Digitalisation Conceptual Framework}

SOEs and state institutions, which are spread across all sectors of the industry, are also widely affected by the 4IR. Consequently, the chances of survival to some which are ailing could be on 4IR adoptions, as the legacy methods or styles might not be applicable, e.g. traditional posting of letters is almost extinct. Having studied the literature on existing frameworks discussed below, this research reused and extended some of these frameworks in conjunction with the above propositions to formulate our conceptual framework for SA SOE adoption of digitalisation in the 4IR.

The proposed conceptual SOE framework for digital adoption extents the familiar TOE (TechnologyOrganisation-Environment) framework and applies some variables of the TAM (Technology Acceptance/ Adoption Model) and UTAUT (Unified Theory of Acceptance and Use of Technology) model constructs. These frameworks are briefly discussed below.

The TAM model has been in use for over three decades and stems from work by Davis [24] and coworkers later on [25]. It embodies three main variables, namely, Attitude towards technology, Perceived Usefulness (PU) and Perceived Ease of Use (PEoU).

Later work on technology adoption formulated the UTAUT framework by Venkatesh et al. [26]. It defined a number of components, namely, Behavioral Intention (BI) and Actual Behaviour (AB), Performance Expectancy (PE), Effort Expectancy (EE), Social Influence (SI), and Facilitating Conditons (FC). Its defining formula is denoted as $\mathrm{BI}=\mathrm{PE}+\mathrm{EE}+\mathrm{SI}$, while $\mathrm{AB}=\mathrm{BI}+\mathrm{FC}$. The model also has four extra factors for moderation, namely, age, gender, experience and voluntariness.

The TOE model from which our framework borrows most was originally developed by DePietro, Wiarda and Fleischer in a 1990 book edited by Tornatzky and Fleischer [27]. TOE is used to examine the adoption of ICT products and services. Its variables are three-fold, namely, technological, organisational and environment. These are then used to study ICT adoption, its use and its value creation. The original TOE model is given in Figure 4.

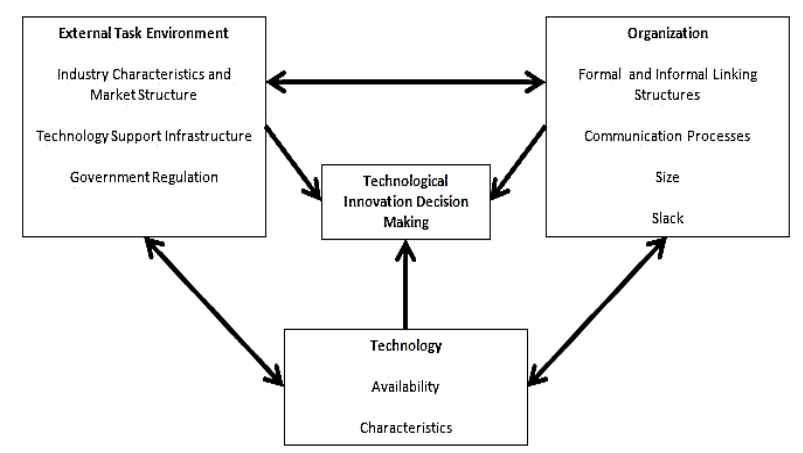

Figure 4: TOE framework of DePietro, Wiarda \& Fleischer [27]

The above three frameworks were developed during the previous industrial revolution and predominately applied in the adoption of traditional ICT rollouts. 4IR digitalisation in which the lines among the physical, digital and biological spheres are blurred through cyber-physical systems (CPSs), requires a change in mindset, necessitating the adaptation of these models with respect to their utility and suitability.

Presumably with increased automation, the services currently offered by SOEs would be improved upon. This may require increased collaboration, especially between government and SOEs. Consequently, the variable of Collaboration (refer Prop 6 above) has been added to the TOE to establish a TOE$\mathrm{C}$ framework depicted in Figure 5.

In the following section we present a discussion of our framework, thereby conducting a theoretical validation thereof in terms of the propositions synthesised from the foregoing literature review. Specifically, the components inductively informed by the propositions are identified and analysed.

\section{Discussion and Validation}

The 4IR Digitalisation framework in Figure 5 is made up of four (4) components as elaborated on below.

\subsection{Organisation, Leadership \& Governance (O in TOE-C)}

- Top management ought to constantly engage with stakeholders, internal and external, so they can be part of the journey to embrace Digitalisation adoption (refer Prop 6 - 6.1 and 6.2).

- From the Board to Executive levels of the SOEs, the organisation structures need to reflect the 


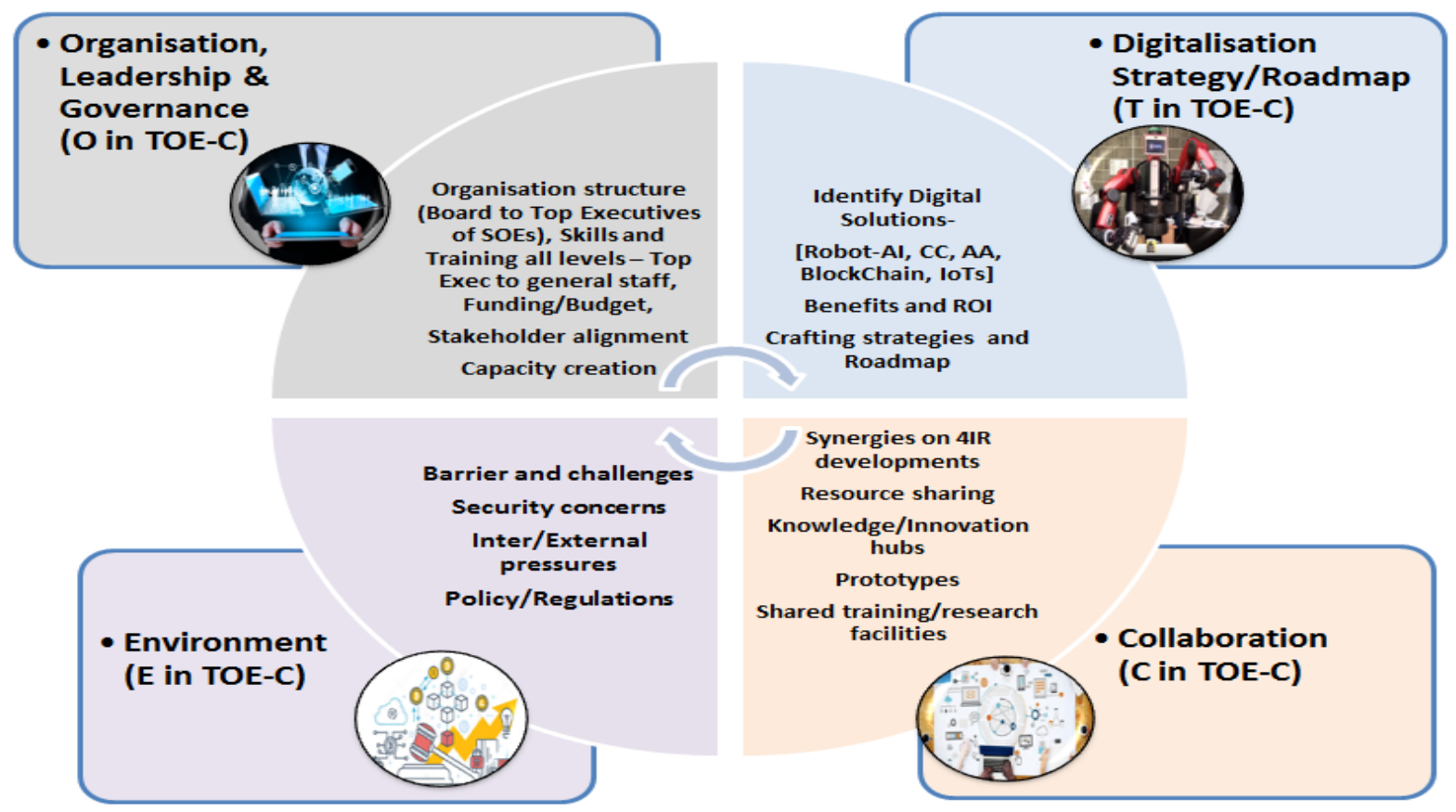

Figure 5: SA SOEs Digitz Conceptual Framework. (Source: Constructed by Researchers)

acceptance of the 4IR and commitment to adoption of Digitalisation (Propositions 1, 4, and 6).

- $\quad$ A budget enabling the appropriate funding should be created through various initiatives, e.g. rent to own of certain product, or pay as you use a service as in Cloud Computing (CC) (Prop 5).

- Commitment for skilling, training and development of firstly the Leadership and later the rest of the organisation should be promoted. Focus should be on the 4IR, which can be achieved in various ways, e.g. secondment of Service providers, collaboration with other SOEs, etc. (Prop 6.2).

\subsection{Digitalisation Strategy/Roadmap ( $\mathrm{T}$ in TOE-C)}

- Digital solutions, i.e. CC, IoT, AI, AA, BLC etc., as indicated in the literature should be identified, evaluated and appropriately adopted by SOEs. The order in which the solutions are adopted is rather crucial as some of solutions may have dependencies on others (Prop 4).

- $\quad$ Exploring, researching and analysing benefits and ROI for suitable Digital solutions (Prop 1 and Prop 3) should be undertaken.
- A clear digitalisation strategy and roadmap with achievable milestones should be developed and supported by the Board and shareholders to empower Executive management to embark on 4IR adoption accordingly (Prop 2 and 4).

\subsection{Environment (E in TOE-C)}

- Addressing barriers and challenges for Digitalisation adoption, the likes of network / bandwidth, security, social impact, service providers, policies / regulation, and internal / external pressures (e.g. political pressures) ought to be well understood and analysed, to mitigate the risks accordingly (Prop 5).

- Digitalisation Governance within SA SOEs ought to be defined, giving cognisance to, and be influenced by the government policy framework on Digitalisation (Prop 2).

\subsection{Collaboration (C in TOE-C)}

- Synergies on 4IR developments should be established by SOEs, by exploring common shared services, shared knowledge / innovation hubs, prototype projects, training centers etc. (Prop 5 and 6.2) 
The World Economic Forum (WEF) executive chairperson Professor Klaus Schwab aptly pointed out that to fully realise the benefits of the 4IR, understanding its concepts and potential is insufficient, it should be "embraced" on a societal level to maximise its benefits through multi-stakeholder collaboration.

The presentations in sections 4 and 5 meet our research objective set out in Section 1.

\section{Summary and Conclusion}

In this paper we unpacked the value proposition of SA SOEs in the context of a developing economy and analysed 4IR literature cognisant of the position of SOEs in the said economies. A number of propositions were formulated from the literature with respect to digitalisation guidelines for future development of SOEs. From these propositions and existing adoption frameworks, notably, TAM, TOE and UTAUT we synthesised a new framework for the digitalisation of SA SOEs. The framework was subsequently validated conceptually through a discussion in which we mapped the propositions developed to the four (4) components of the framework in Figure 5.

SA SOEs are deemed the power houses of the South African economy and they ought to formulate strategies to fully participate as innovators and mass technology developers of innovative products. Their workforces ought to focus on innovation, analytics, and digitalisation researches, development, maintenance and support of these. These can assist in balancing the currently import imbalances of 4IR related products.

It is anticipated that for many the future of new kinds of jobs as Digitalisation advances will be around three categories as alluded by [28], of creators - people designing and creating highly-tailored products and services, composers - likes tours of galleries, entertainment etc. and coaches - wellness coaches at all levels of life. Furthermore, they alluded that technology can reward organisations that embrace it but can also marginalise those who ignore it. As quoted by Hagel III, "the bottom line is that technology is unleashing market forces that can reward those who address these challenges and marginalise those who ignore them. And, far from depriving us of work and squashing our humanity, technology can provide us with the opportunity to focus on work and activities that will help us to achieve more and more of our potential. What better service could technology provide?” [28].

Our 4IR Digitalisation framework is, therefore, imperative for the proper approach to formulating and executing strategies for Digitalisation efficiently and effectively. The framework will, therefore, focus on the following elements: capacity creation - brain house, research, training, secondments, etc.; crafting strategies - revisit current strategies, organisation structures, flexibilities; digital leadership/drivers, technology identification - Cloud Computing, AI, Advanced Analytics, IoTs, Blockchain, etc.; Implementation funding, re-organisation, governance, social aspects, and so forth.

As future work, the conceptual framework will be validated with ICT- and Business executives of SOEs and service providers in months to come. It will also be imperative to exercise the framework among companies in industry to determine the scalability thereof. Additionally, SOE benefits and challenges to be derived from the 4IR should be explored.

\section{References}

[1] Davis Nicholas. "Fourth Industrial Revolution WEF Agenda”, Weforum, 2016. Retrieved October 21, 2018 from https://www.weforum.org/agenda/2016/01/whatis-the-fourth-industrial-revolution/

[2] World Bank. “Gross Domestic Product 2017”, pp. 1-4, 2018. Retrieved 18 July 2018 from http://databank.worldbank.org/data/download/GDP.pdf

[3] Weforum GIT. "Global information technology report on SA”, Weforum, 2016. Retrieved July 5, 2018 from http://reports.weforum.org/global-informationtechnology-report2016/economies/\#indexId=NRI\&economy=ZAF

[4] Mark Saunders, Philip Lewis, and Adrian Thornhill. "Research Methods for Business Students", (7 th ed.). Pearson Education Limited, Harlow, 2016.

[5] Abiodun Bayode, John A. van der Poll and Rohith R. Ramphal (2019) " 4 th Industrial Revolution: Challenges and Opportunities in the South African Context”, Conference on Science, Engineering and Waste Management (SETWM-19), pp. 174 - 180, 18 - 19 November 2019.

[6] SA Dept of Science and Technology. "White Paper on Science, Technology and Innovation”, September 2018. Retrieved from https://www.dst.gov.za/images/2018/white-pate-onSTI-7_09-FINAL.pdf

[7] State Owned Enterprises. Retrieved 30 June 2020 from https://en.wikipedia.org/wiki/Stateowned_enterprises_of_South_Africa.

[8] Weforum DCR. "Digital Competitiveness Ranking of SA”, Weforum. Retrieved 8 August 2018 from https://0-worldcompetitiveness-imdorg.oasis.unisa.ac.za/countryprofile/ZA/digital

[9] Nyawo Gumede. "Prescriptions of the National Development Plan for State-Owned Enterprises in South Africa: Is Privatisation an Option?” 51(2), pp. 265-277, 2016.

[10] Krish Kumar. "The 4th Industrial Revolution”, CIGFARO 18(3), pp. 16-21, 2018.

[11] Krish Chetty, Urvashi Aneja, Vidisha Mishra, Nozibele Gcora, and Jaya Josie. "Bridging the Digital Divide: 
Skills for the New Age”, Econ. Open-Access, OpenAssessment E-Journal 12, 2018-24, pp. 0-21, 2017.

[12] WikipediaG20. "Wiki G20”, Wikipedia, 2018.

[13] Peter Minor, Terrie Walmsley, and Anna Strutt. "Stateowned enterprise reform in Vietnam: A dynamic CGE analysis”, J. Asian Econ. 55, pp. 42-57, 2018. DOI: https://doi.org/10.1016/j.asieco.2017.09.002.

[14] Teng Li and Ataur Belal. "Authoritarian state, global expansion and corporate social responsibility reporting: The narrative of a Chinese state-owned enterprise", Accounting Forum, 42(2), pp. 199-217, 2018.

[15] L Jeremy Clegg, Hinrich Voss, and Janja A. Tardios. "The autocratic advantage: Internationalization of stateowned multinationals”, J. World Bus. 53(5), pp. 668681, 2018. DOI: https://doi.org/10.1016/j.jwb.2018.03.009

[16] Joseph M Woodside, Jr Augustine, Fred K, and Will Giberson. "Blockchain Technology Adoption Status and Strategies", ABI/INFORM Collection - ProQuest. J. Int. Technol. Inf. Manag. Vol. 26(2), pp. 65-93, 2017. Retrieved from https://search-proquestcom.proxy006.nclive.org/abicomplete/docview/198160 9921/fulltext/29FC2E755E824FE2PQ/1 ?accountid=83 37.

[17] Kumar Ravi, Yogesh Khandelwal, Boora Shiva Krishna, and Vadlamani Ravi. "Analytics in/for cloudan interdependence: A review”, J. Netw. Comput. Appl. 102, pp. 17-37, 2018. DOI: https://doi.org/10.1016/j.jnca.2017.11.006.

[18] Luca Anselma, Alessandro Mazzei, and Franco De Michieli. “An artificial intelligence framework for compensating transgressions and its application to diet management”, J. Biomed. Inform. 68, pp. 58-70, 2017. Retrieved from http://dx.doi.org/10.1016/j.jbi.2017.02.015.

[19] Thomas H Davenport and Rajeev Ronanki. "Artificial Intelligence for the Real World”, Harv. Bus. Rev., pp. 108-117, 2018. DOI: https://doi.org/10.1016/S00163287(03)00029-6.
[20] Jayavardhana Gubbi, Rajkumar Buyya, Slaven Marusic, and Marimuthu Palaniswami. "Internet of Things (IoT): A vision, architectural elements, and future directions”, Futur. Gener. Comput. Syst. 29(7), pp. 1645-1660, 2013. DOI: https://doi.org/10.1016/j.future.2013.01.010.

[21] Luigi Atzori, Antonio Iera, and Giacomo Morabito. "Understanding the Internet of Things: definition, potentials, and societal role of a fast-evolving paradigm”, Ad Hoc Networks 56, pp. 122-140, 2017.

[22] Cjb Le Roux and Nina Evans. "Can cloud computing bridge the digital divide in South African secondary education?”, Sage Perspectives, 27(2), pp. 109-116, 2011. DOI:https://doi.org/10.1177/026666691140150.

[23] Nishana Bhogal. "The role of the Square Kilometre Array in South Africa's economic development strategy”, S. Afr. J. Sci., 2018.

[24] Fred D. Davis. “A Technology Acceptance Model for Empirically Testing New End-User Information Systems”, January 1985.

[25] Fred D. Davis, Richard Bagozzi and Paul R. Warshaw. "User Acceptance of Computer Technology: A Comparison of Two Theoretical Models”, Management Science, 35(8), pp. 982-1003, 1989. DOI: 10.1287/mnsc.35.8.982.

[26] Viswanath Venkatesh, Michael G. Morris, Gordon B. Davis and Fred D. Davis "User acceptance of information technology: Toward a unified view”, MIS Quarterly: Management Information Systems, 27(3), pp. 425-478, 2003. DOI: 10.2307/30036540.

[27] Rocco DePietro, Edith Wiarda and Mitchell Fleischer. "The context for change: Organization, technology and environment”, in Tornatzky, L. G. and Fleischer, M. (Eds.) The processes of technological innovation, Lexington Books: Lexington, MA., pp. 151-175, 1990.

[28] John Hagel III. "3 Kinds of Jobs That Will Thrive as Automation Advances”, HBR, 2018. 